\title{
Solitons and Breather type solutions of some nonlinear equations by the Sine-Cosine method.
}

Sidheswar Behera ${ }^{1}$ and jasvinder singh virdi ${ }^{1}$

${ }^{1}$ Veer Surendra Sai University of Technology

May 24, 2020

\begin{abstract}
In our recent work, we study a few nonlinear time evolution equations by the sine-cosine method and obtained a variety of generalized solitary and periodic solutions with distinct physical structures. The solutions include periodic solutions, soliton solutions, symmetric periodic soliton solutions, double periodic solutions, multiple soliton solutions, breather solutions, and kink type solutions.
\end{abstract}

\section{Hosted file}

sine cosine mcm.pdf available at https://authorea.com/users/325700/articles/453706-solitonsand-breather-type-solutions-of-some-nonlinear-equations-by-the-sine-cosine-method

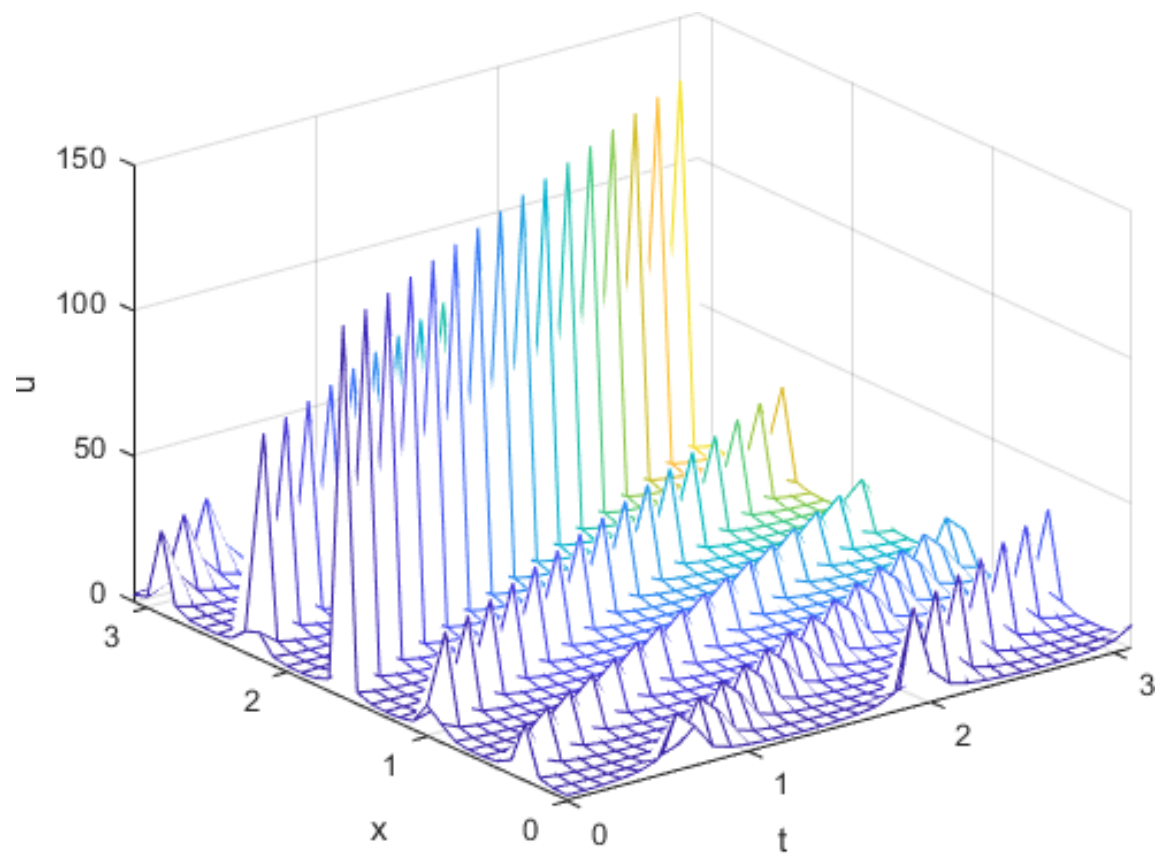



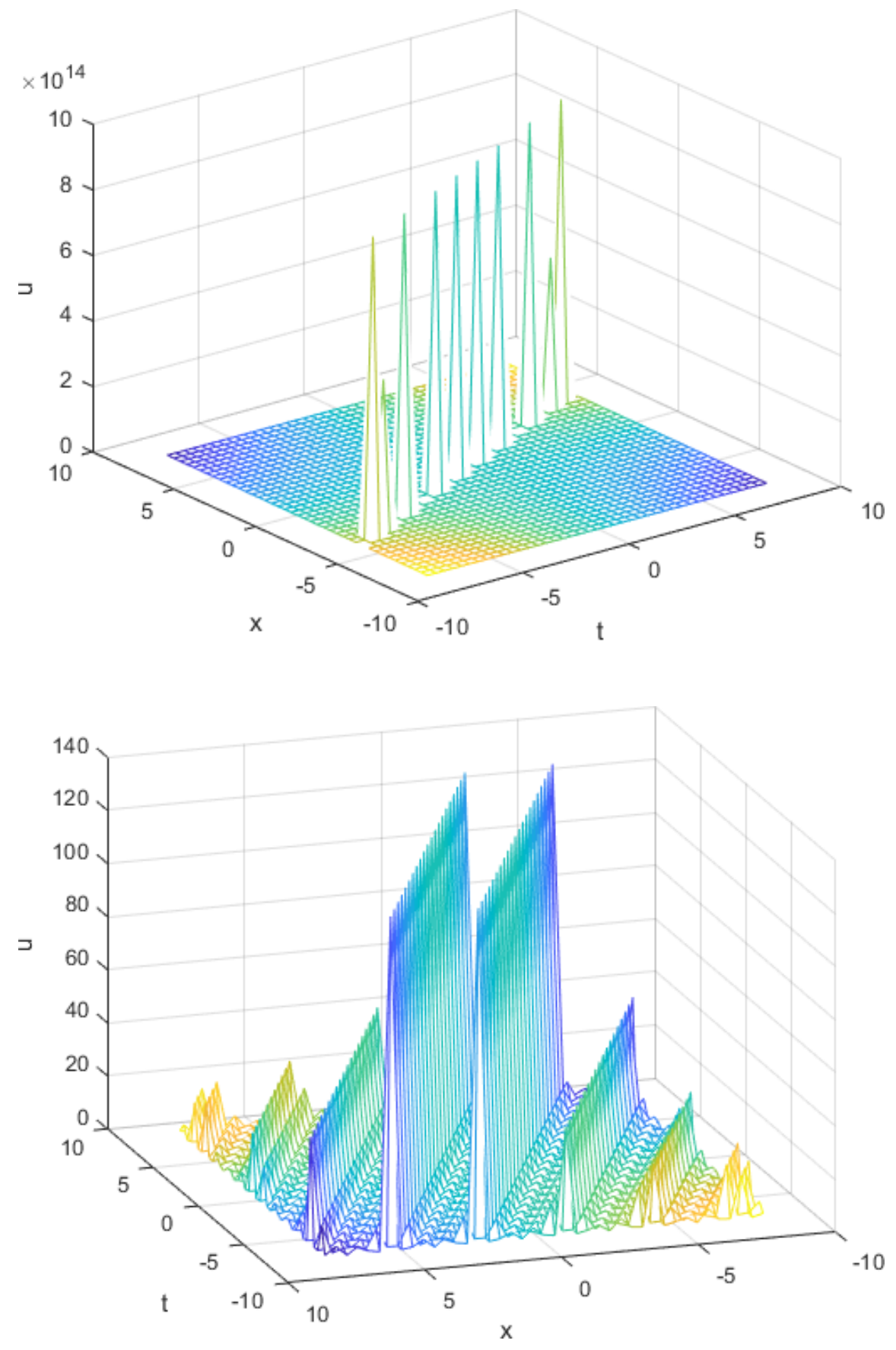

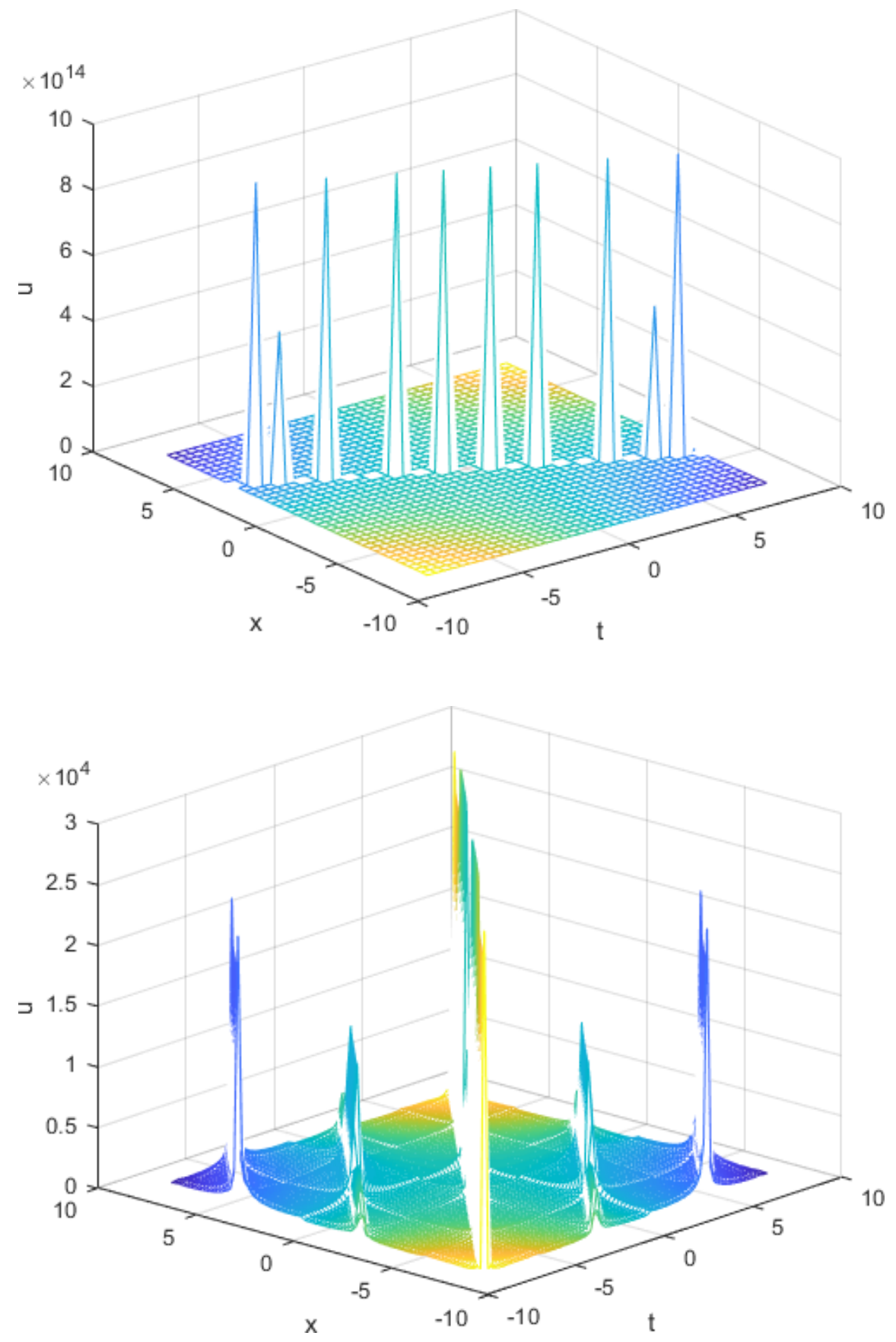

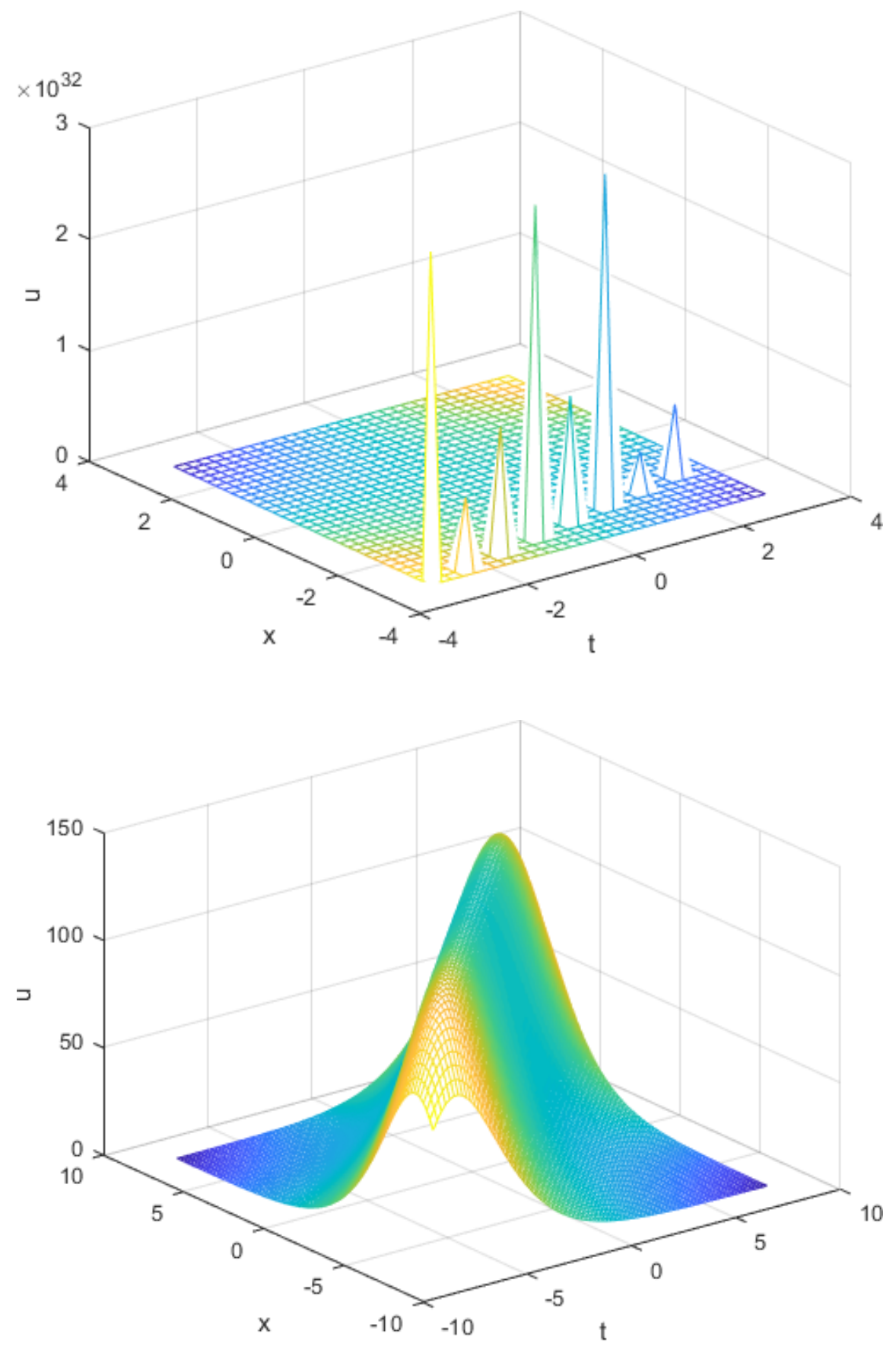

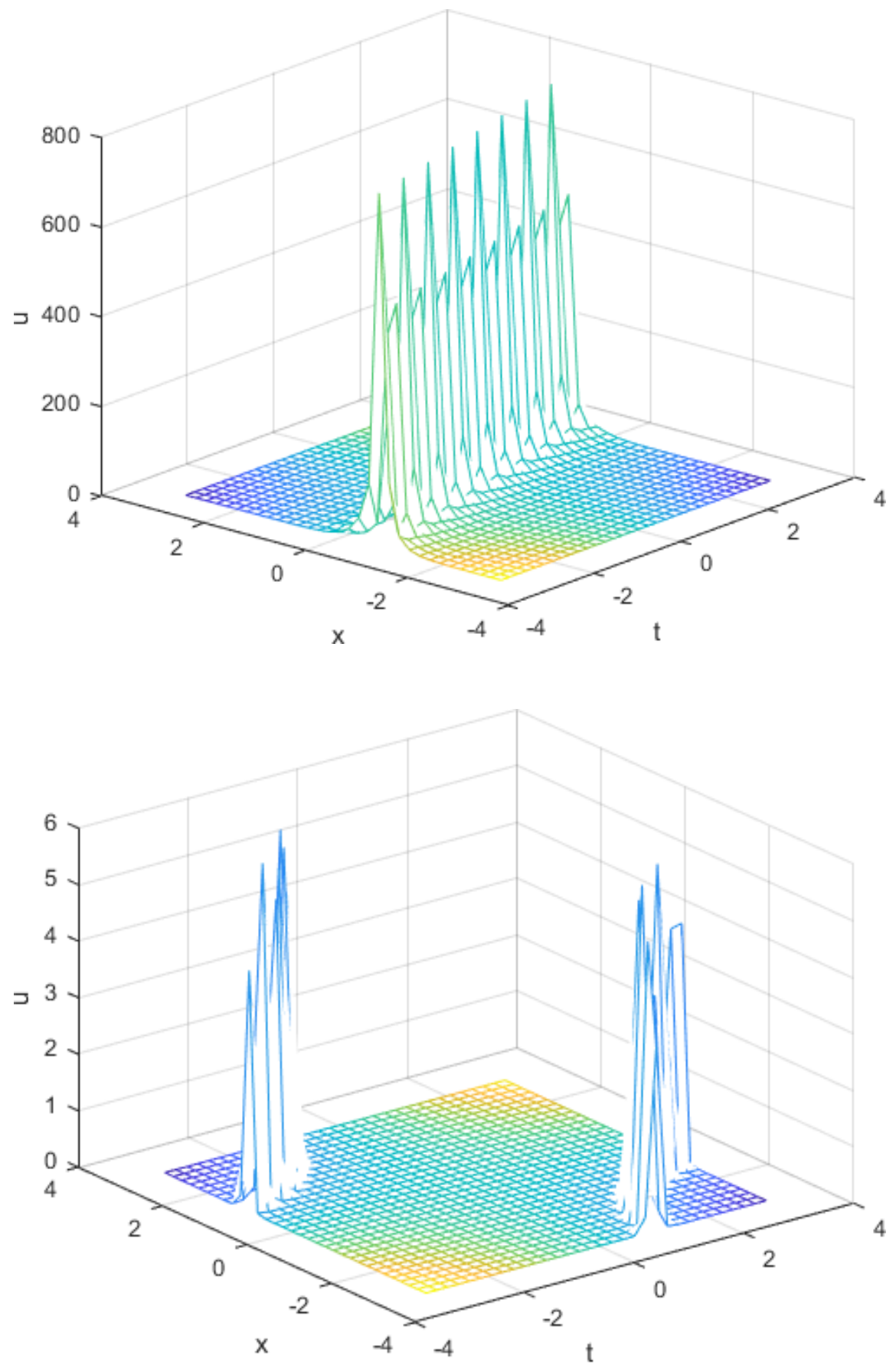

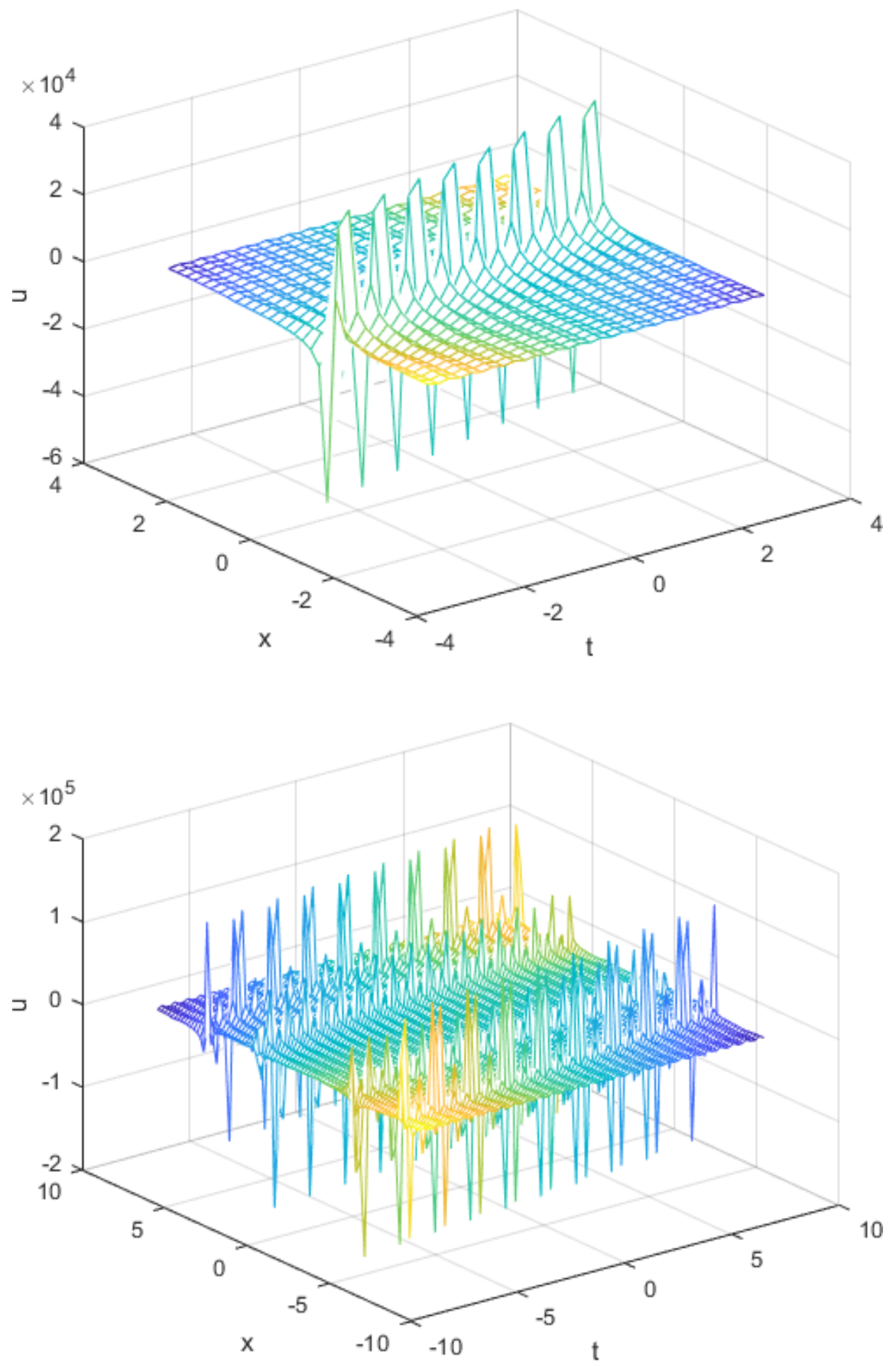

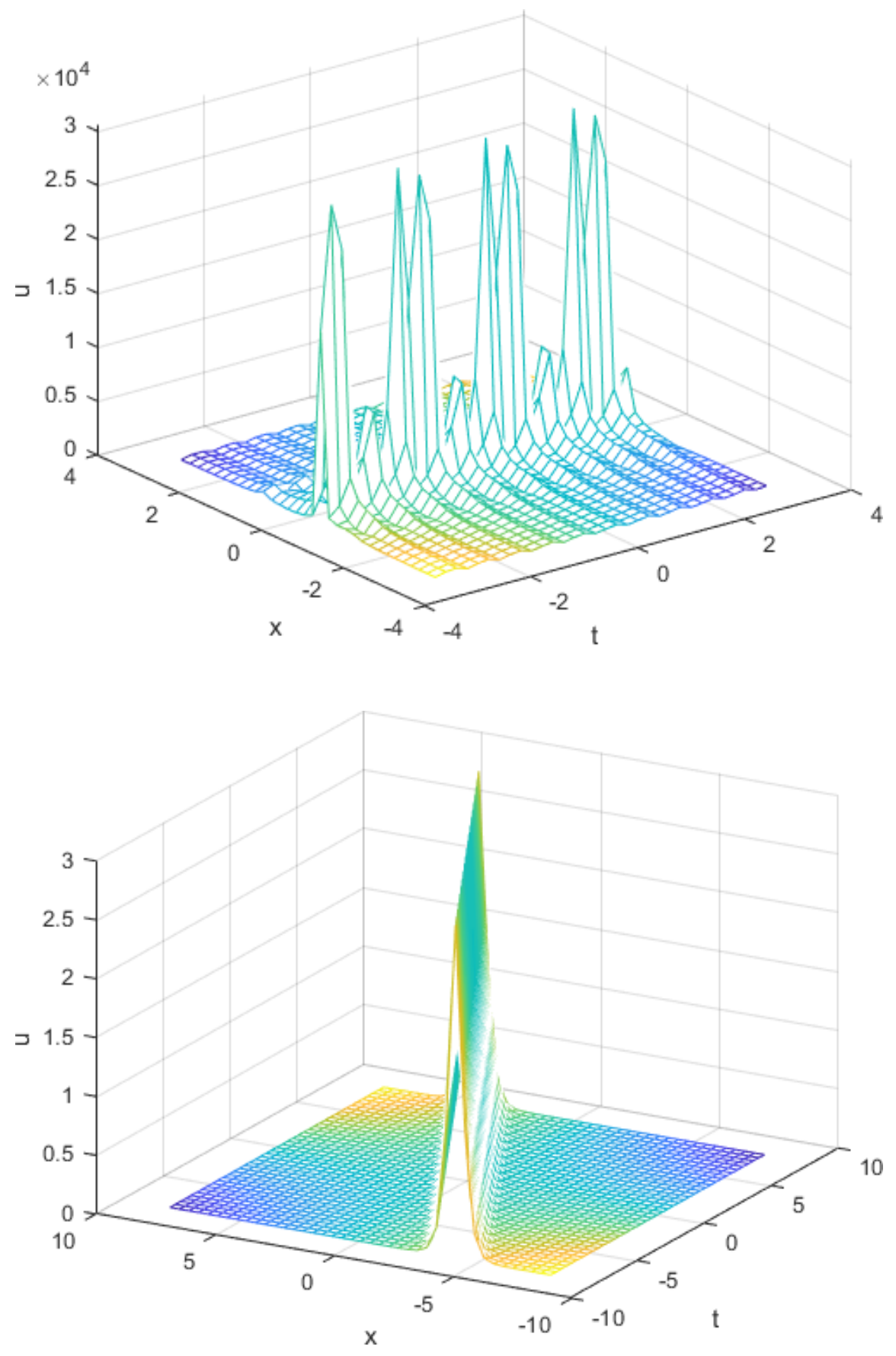

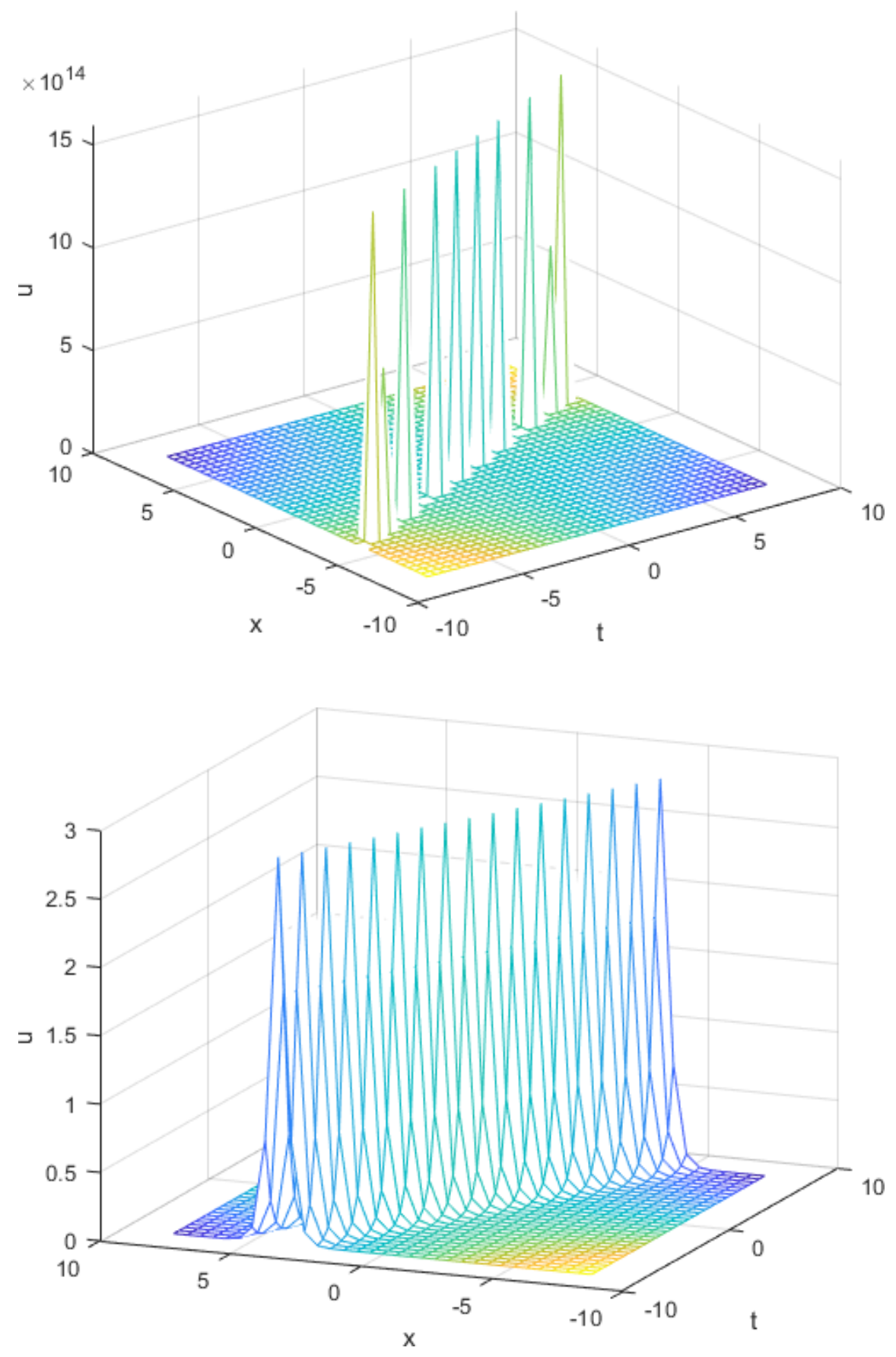


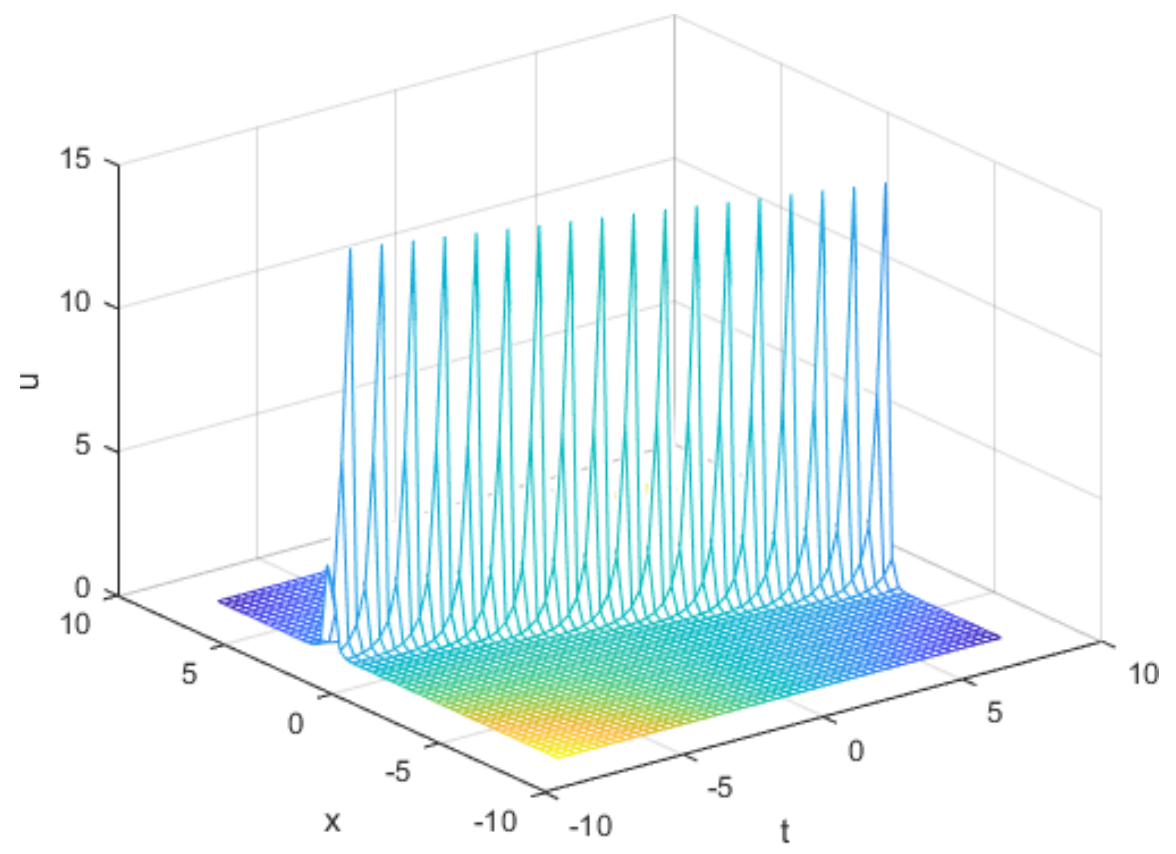

